\title{
Non-Operative Treatment Versus Steroid Injections in the Management of Unicameral Bone Cysts
}

\author{
WI Faisham*, M Med Orth, AH Nawaz*, M Med Orth, AM Ezane*, M Med Rad, W Zulmi*, MS Orth, \\ S Ibrahim**, FRCS, AR Abdul Halim**, MS Orth \\ *Department of Orthopaedics, Unversiti Sains Malaysia, Kubang Kerian, Malaysia \\ **Department of Orthopaedics and Traumatology, Universiti Kebangsaan Malaysia Medical Centre, \\ Kuala Lumpur, Malaysia
}

\begin{abstract}
The cases of nine patients with unicameral bone cysts were reviewed from two orthopaedic centres. In one hospital, five patients received serial steroid injections, and at the other hospital four patients were treated conservatively following fractures. In the steroid injection group, three cases were in the proximal femur and two in the proximal humerus. The five steroid injection patients showed radiological evidence of cyst healing within six months of treatment. Subsequently four of the patients showed a satisfactory radiological outcome after a year and complete resolution after 2 years. In the conservative group, all four cases were in the proximal humerus. Persistent cystic lesions were observed in all four patients and two was complicated by another fracture within six months.
\end{abstract}

\section{Key Words:}

Unicameral Bone Cysts, fracture, Steroid Injections

\section{INTRODUCTION}

Unicameral bone cyst (UBC) is described as a central metaphyseal cystic lesion of the bone with serum fluid content. Diagnosis is typically based on diagnostic imaging features, age, localisation at proximal humerus and femur, and the absence of symptoms until pathological fracture development ${ }^{1}$. Radiographic imaging shows a smooth, continuous, well-defined thin cortex with no significant septation.

UBCs are often asymptomatic and are only discovered due to pain from an associated fracture. The lesion is most active during skeletal growth and usually heals spontaneously at maturity ${ }^{1,2}$. The only indication for treatment of a UBC is to decrease the potential risk of pathologic fracture, as they are otherwise benign and self-limiting. Two-thirds of UBC patients present with a fracture, which stimulates the cyst to heal ${ }^{1,2}$. The preferred method of treatment remains controversial $^{3,4,5,6}$. In the past, treatment consisted of curettage and bone grafting with a recurrence rate of approximately $30 \%$. At present, the mainstay of treatment is minimally invasive and has a significant success rate: steroid injections; administration of autologous bone marrow, decalcified bone matrix or sclerosing agent; and minimally invasive stabilisation ${ }^{3,4,5,6}$.

\section{MATERIALS AND METHODS}

In all cases, diagnosis of UBC in all cases was based on diagnostic imaging features, age, localisation at the proximal humerus and femur, and absence of symptoms until development of pathological fracture. Only radiographic images showing a smooth, continuous, well-defined thin cortex with no significant septation were included in the series. Diagnosis was substantiated by clear serosanguineous fluid extracted before injection of steroids.

Five patients underwent serial steroid injections for UBC at the Hospital Universiti Sains in Malaysia. There were three males and two females with age range between 10 to 16 years. Three cysts were located at the proximal femur and another two at the proximal humerus. Three patients presented with pathological fracture and two with deepseated dull pain. Two patients with proximal humerus fractures were treated with U-Slab and one patient with a femur fracture was treated with traction followed by cast. There was no radiological improvement of the lesion on follow-up despite fracture and the patients were subsequently managed with steroid injection. The fallen fragment sign (cortical fragment fracture fallen into the base of the lesion) was observed in one patient with a proximal femur fracture.

Steroid injections were administered in the operating room with the patient under general anaesthesia. Fluoroscopic guidance was used to visualize the 18 gauge spinal needle as it penetrated the cortex overlying the lesion. Direct aspiration of the cystic fluid was performed until fresh bleeding was seen and a second needle placed away from the 
Table I: Series of 5 patients treated with steroids injection

\begin{tabular}{|ccccccccc|}
\hline No & Age & Sex & \multicolumn{1}{c}{ Site } & Presentation & $\begin{array}{c}\text { Steroids } \\
\text { Injections } \\
\text { (Number } \\
\text { procedures) }\end{array}$ & $\begin{array}{c}\text { Radiological } \\
\text { Outcome } \\
\text { (Grade Neer }{ }^{2,3} \text { ) }\end{array}$ & $\begin{array}{c}\text { Follow Up } \\
\text { (Months) }\end{array}$ & $\begin{array}{c}\text { Outcome } \\
\text { (Symptoms) }\end{array}$ \\
\hline 1 & 11 & M & Rt femur & Pain & 3 & 1 & 36 & Nil \\
2 & 10 & M & Lt humerus & Fracture & 3 & 2 & 17 & Nil \\
3 & 12 & F & Rt femur & Pain & 3 & 1 & 22 & Nil \\
4 & 13 & M & Lt femur & Fracture & 2 & 2 & 12 & Nil \\
5 & 16 & F & Rt humerus & Fracture & 3 & 1 & 27 & Nil \\
\hline
\end{tabular}

Table II: Series of 4 patients treated conservatively

\begin{tabular}{|ccccccccc|}
\hline No & Age & Sex & Site & Presentation & $\begin{array}{c}\text { Radiological } \\
\text { Outcome } \\
\text { (Grade Neer, }\end{array}$ & $\begin{array}{c}\text { Refracture } \\
\text { (Months) }\end{array}$ & $\begin{array}{c}\text { Follow Up } \\
\text { (Months) }\end{array}$ & $\begin{array}{c}\text { Outcome } \\
\text { (Symptoms) }\end{array}$ \\
\hline 1 & 11 & M & Humerus & Fracture & 3 & - & 24 & Nil \\
2 & 9 & M & Humerus & Fracture & 2 & 6 & 12 & Refracture \\
3 & 10 & F & Humerus & Fracture & 2 & - & 36 & Nil \\
4 & 13 & F & Humerus & Fracture & 3 & 5 & 36 & Refracture \\
\hline
\end{tabular}

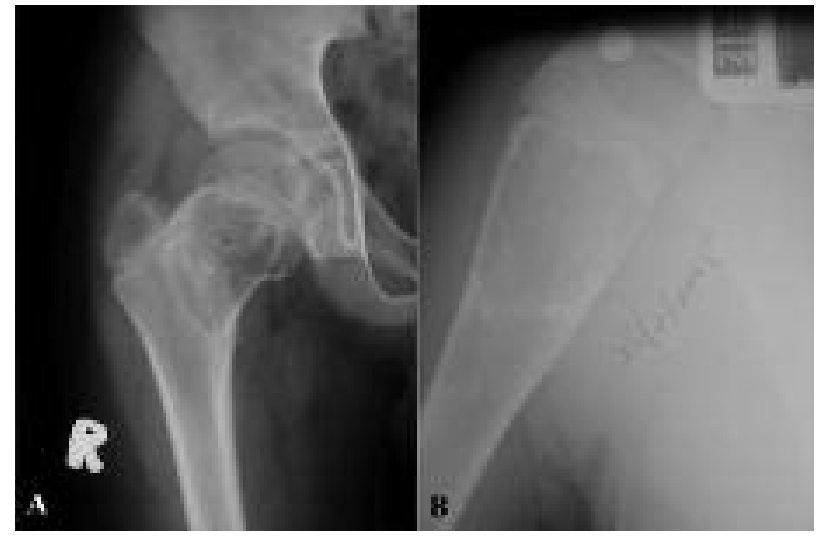

Fig. 1 (A\&B): The radiographs show complete healing of UBC (Grade 1 Neer's) 8 months following serial steroids injection.

aspiration needle was used to inject the steroid. We used 80$200 \mathrm{mg}$ of Depo-Medrol (Upjohn, Kalamazoo) depending on the size of the patient and the specific lesion as well as the age of the patient. Three to four injections were administered to all patients over a six month period.

Four patients at Hospital Universiti Kebangsaan in Malaysia were treated conservatively with U-slabs following pathological fracture of the proximal humerus.

All patients in this case series were evaluated for clinical and radiological improvement every 3 months. Healing of the cyst was defined as obliteration of cyst by new bone formation. Radiological healing was evaluated according to the Neer grading systems ${ }^{2}$.

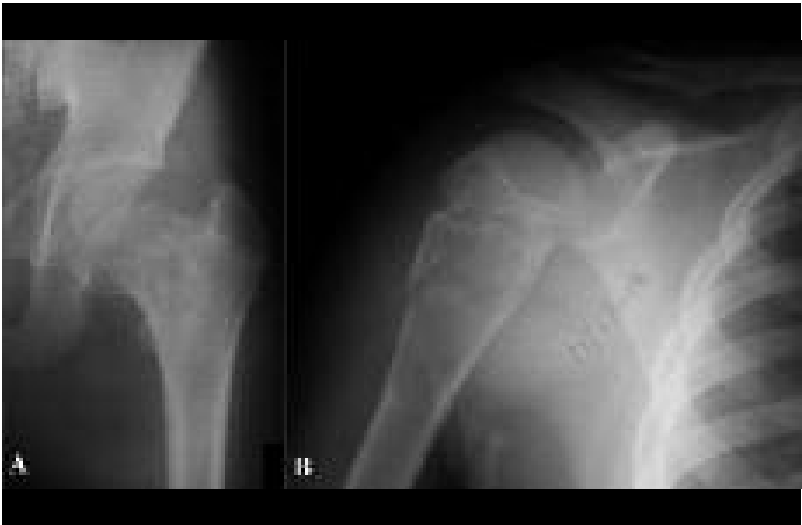

Fig. 2 (A\&B): The radiographs show incomplete healing of UBC (Grade 3 Neer's) 24 months following fracture and conservative treatment.

\section{RESULTS}

In the steroid group four cases had satisfactory radiological and clinical outcomes following steroid injections. These patients were able to achieve normal daily activities without pain at last follow-up. Radiological healing of the cyst was observed in all patients (Grade 1 and 2 Neer). One case was still in the early treatment phase, however already showed grade 3 radiological findings. (Table I) (Figure 1)

In the conservative treatment group, fracture healing was observed at 8 weeks and all patients were fully functional at three months. Radiological healing of the cyst around the fracture area was present but not complete in all patients. Two patients had partial radiological healing (grade 2) and 2 patients had a remaining cyst of grade 3. Two patients subsequently developed another fracture at a different site within six months and healed with further conservative treatment. (Table II) (Figure 2) 


\section{DISCUSSION}

$\mathrm{UBC}$ is asymptomatic in the majority of patients. The only indication for a surgical procedure in UBC treatment is either when the patient has high potential for development of a pathological fracture or pain. Small lesions in non-weight bearing bones can be treated expectantly, but operative treatment should be considered in cases with large cysts situated in high stress areas ${ }^{1,2}$. Surgical options include aspiration of cystic fluid with injection of steroids or curettage and bone grafting with or without internal fixation $^{3-7}$. Recently, synthetic calcium sulphate with bone morphogenetic protein for cyst filler and placement of cannulated screw for continuous fluid drain have been reported to have good success ${ }^{3-6}$. Pathological fractures in the upper extremity can be treated non-operatively as the fracture itself may initiate healing. In our patients, cyst healing was not complete in all patients treated conservatively, however, all patients had a good clinical outcome.
Many authors have advocated serial steroid injections as a primary treatment of UBC. Clinical and radiological improvement was reported to be as high as $95 \%$ and was comparable with curettage and bone grafting ${ }^{7}$. It is a minimally invasive procedure, technically not demanding, and has less morbidity. All cases in our series responded well to serial steroid injections. The technique is hypothesized to work by an anti-prostaglandin effect; prostaglandin has been identified as present in the cystic fluid, regulating osteoclastic activity ${ }^{8}$. In addition, aspiration decreases the pressure of the cyst which is thought to cause focal bone necrosis and fluid accumulation ${ }^{5,6,8}$.

The limitations of this study are the small number of patients and the fact that most patients were not skeletally mature.

\section{CONCLUSION}

Fractures through UBC in the upper extremity can be treated non-operatively. However, steroid injection is an effective option to hasten healing and should be considered as a primary treatment of unicameral bone cyst. 


\section{REFERENCES}

1. Campanacci M, Capanna R, Picci P. Unicameral and aneurysmal bone cysts. Clin Orthop Relat Res 1986; 204: 25-36.

2. Neer CS, Francis KC, Marcove RC,Terz J, Carbonara PN. Treatment of unicameral bone cysts: A follow up study on one hundred seventy-five cases. J Bone Joint Surg Am 1966; 48-A: 731-45.

3. Di Bella C, Dozza B, Frisconi T, Cevolani L, Donati D. Injection of demineralised bone matrix with bone marrow concentrate improves healing in unicameral bone cyst. Clin Orthop Relat Res 2010; 468: 3047-55.

4. Hou HY, Wang CT, Chang SM, Lin WH, Yang RS. Treatment of unicameral bone cyst: a comparative study of selected technique. J Bone Joint Surg 2010; 92A(4); 855-62.

5. Mik G, Arkader A, Manteghi A BS, Dormans JP. Result of a minimally invasive technique for treatment of unicameral bone cysts. Clin Orthop Relat Res 2009; 467: 2949-54.

6. Sung BS, Anderson ME, Zurakowski D, Hornicek FJ, Gebhardt MC. Unicameral bone cyst - A retrospective study of three surgical treatments. Clin Orthop Relat Res 2008; 466: 2519-26.

7. Oppenheim WL, Galleno H. Operative treatment versus steroid injection in the management of unicameral bone cyst. $J$ Pediatr Orthop 1984; 4: 1-7.

8. Cohen J. Simple bone cysts. Studies of cyst fluid in six cases with a theory of pathogenesis. J Bone Joint Surg 1960; 42A: 60916. 